jecting the patient to an operation. In those and an increasing lameness from attempted use cases in particular in which the suspicion of that may be avoided.

typhoid fever is present, the aldomen should not be opened unless the indications are strong. When, in spite of repeated examinations and the greatest care, the surgeon is convinced that ty. phoid fever is not present, exploration, even if it proves him wrong and shows that typhoid does really exist, loses the sting of carelessness and haste. The blunders that mortify are those which would be unnecessary were the examination painstaking.

\title{
UNNO'TICED FRAC'TURES IN CIILDREN.
}

IIV l. J. Comon, M.W., AND R. H. Vosk, M.D., Boston.

'Tin: title of this paper refers not to the gross errors in diagnosis, which are not common, but to those fractures which may readily be overlooked because of the relative absence of symptoms. Now that fractures are being studied more systematically with the aid of the $x$-ray, we are in position to confirm what has long been held but insuficiently demonstrated, - that fractures not infrequently exist with but slight symptoms, that mere cracks may readily be overlooked, that incomplete fractures or complete fractures without displacement are commoner than was formerly supposed, and that such fractures may not infrequently exist without being suspected by the patient. That even the physician may overlook them is shown by the not inconsiderable number of cases that come into the public clinics which have already been soen, but apparently not diagnosticated, by the family physician.

This overlooking of fractures is especially likely to happen in children, not only because they are less able to be exact in their complaints, but even more because many fractures in children show disproportionately little pain or reaction. Why this is so is somewhat hard to explain. To be sure, the violence producing these fractures is usually not great, and in green-stick and other incomplete fractures there is damage only to a portion of the cortical bone, practically without injury to the periosteum and soft parts; but even if the fracture be complete, the child is often surprisingly tolerant.

It is only when one happens to be seeing a considerable number of injuries in young children that one comes to appreciate that a relative lack of symptoms does not bar out fracture. If this is not borne in mind and a child is brought to the surgeon with the question of injury to a limb which shows no deformity and can still be used fairly freely withont any considerable pain, it may readily happen, and does happen, that it be let go without the detailed examination such cases deserve, only to have the existence of the fracture discovered days or weeks later. It is true that such fractures are of minor importance and that the end result is good anyhow, but neglect of fixation usually involves excessive callus formation

It is the belief of the writers that the danger of overlooking these cases lies not in the actual difi. culty of diagnosis, but in the fact that the relative frequency of such fractures is not borne in mind, and in our unconscious adherence to the general notion of disability and pain as accompaniments of fracture. There is also a tendency to overlook the relative frequency of complete or incomplete fractures, in children, in which there is little or no displacenent and none of the bowing of the classical "green-stick" which most men in. stinctively expect as the form of fracture especial to children. One of the writers has in a previous note called attention to these forms of "subperiosteal" fracture." They are particularly common in children, and most of the cases to be cited would properly come in this class.

In the subjoined list of cases all questions of doubt were submitted to the skiagraph, but in all cases only after the clinical diagnosis of fracture had been made. In only one case seen by the writers did the skiagraph fail to confirn the clinical diagnosis of fracture. ${ }^{2}$

In examining these patients, even if there be no complaint of pain, there is nearly always some difference in the use of the limb on the two sides or some limitation of range of motion. In some cases this is due to reflex muscular spasm of the same sort as is seen in joint disease. In part, the limitation is voluntary as a result of pain, but in many cases there is only a curious disinclination to use the limb apart from any sign of pain whatever. With a fractured clavicle, for instance, it happens that if the child be asked to raise both arms he lifts one hardly more than half as high as the other, nor can he upon urging raise it any further, though the arm can he moved to the full limit passively without pain or spasm. The same painless or seemingly painless disability is seen in the limp of certain tractures of the tilsia, and in the loss of grasp in case of green-stick fracture in the forearm. The writers have seen no explanation of this. It is hard to say whether it is to be classed as a reflex or as a voluntary inhibition - certainly if voluntary it is not necessarily a result of pain consciously felt.

Passive motion in these cases may or may not be painful. If painful, the pain is likely to be only on extreme flexion or extension, etc. In some cases no complaint of pain can be brought out by movement.

On palpation, however, there will always be found a localized tenderness, which may be slight though definite. Sometimes there is deformity appreciable by careful palpation (typical greenstick fractures with deformity are, of course, not likely to be overlooked); now and then we find a wholly unexpected crepitus.

Frequently, where days or even weeks have elapsed, we find a well-defined small (usually ring-

1 Boston Medical and Surgic:al Journal, Nov. 29, 1900.

2 This case, supposerl to be a fracture, proved to be a localized periostitis of traumatic origin. 
like) callus and local tenderness. Where this condition exists the skiagraph is hardly needful to an absolute diagnosis; where there is only local tenderness with a history of trauma, a diagnosis of probability is justified and may be made with a good deal of confidence.

In the abridged histories of cases ${ }^{8}$ which follow, the records of treatment are omitted; in all cases it was a matter of simple fixation for two to four weeks, and in all cases practically perfect results were attinined.

Cask I. A. 11., age 4 years. Fell one week ago. Yesterday mother first noticed in lifting the child by the left hand that she complained of pain. Examination showed an obvious callus at the middle of the left clavicle - not very tender - no displateement, but. definite crepitus, and on forced manipulation the fragments could be made to move on one another. Evidently this was a subperiosteal complete fracture. All motions of the arm and shoulder carried out by the child without wincing.

Cass II. L., ago 1 y years. Fell seven days ago. Ilother noticed no immediate disability, but siuce then the child always cries when dragged by left arm. Child lifts arm to face and uses it fairly freely. There is a transverse midelavicular fracture with freely movable fragments.

Cases 1II. A. C., ane 6 years. Child with hip disease. Supposed to have fillen while in the hospital ward. On reaching lome could not use crutches. 'Twelve day's later' came to the Out-Patient Department. Diagnosis of "nerve aflection" said to havo been made by the family doctor. l'roved to have an obvious fracture of the claviclo without any cousiderable displacement; marked callus, no mobility. Disability relatively slight.

Case IV. IV. D., agre 1 ; years. Fell yesterday out of his brother's arms. Nothing noticed except that child cries as if in pain when lifted. No swelling. All motions can be carried out passively and apparently without pain. Active motion somewhat limited. Over the centre of the right elavicle is a point which is particularly tender and where there seems to be a little thickening. No mobility. Nine days later the callus was increased and detinite.

Cass: V. P. L., age 4 years. Had a fall, the mother thinks, about four weeks ago ; for the last 2 weeks has complained of pain in the shonlder, and the shoulder has been "stiff." No treatment. Examination shows fracture of clavicle near the middle - solid callus the size of a finger.

Casl: VI. J. K., age 3 years. One week ago fell out of bed; sinee then has cried when handled and cried out at times at night. No treatment. Fracture of clavicle at the outer and middle third,- a little displacement of ends, - now firm, but there was evidently a complete fracture.

CAsE VII. J. S., age 4 years. Fall of unknown date a few days ago. II is had no treatment. Incomplete fracture a little outside the midelle of the right clavielo with marked callus. Little tenderness. Disability only partial.

Case VIII. G. M., age 3! years. Foll 4 days ago. No treatment. Complains now of some pain. Incomplete fracture of right clavicle, middle third. MIoderate callus.

CAsE IX. G. H., age 4 years. Foll 3 days ago. Since then no complaint except when lifted. No treatment. Callus at outer and middle thirds of right clavicle. No crepitus; localized tendurness is moderate. Carries out all motions voluntarily, but the range of motions less on tho right. No rosistance to passive motion. Neither active nor passive motion painful. s Seen by the writers at the City and Children's hospitals, and
in the $x$-ray room of the lioston Dispensary, and reported by courtesy of the surgical stafis of these institutions.
Casi X. A.M., ago 5 years, Fall 5 days ago. No treatment except rubbing. Has had a little piain, refered to somewhere aboit the shoulder. Ripht chavicle shows definito callus in middle. No mobility of fragments.

Case XI. M. M., age $12-12$ years. Three weeks ago fell on the floor. II als not used the right arm freely since. Examination shows a green-stick fracture of both radius and ulna on the right; ether; reduced.

Case XII. W. B., age 1 4-12 years. Foll down statrs 4 day's ago. No treatment. Apparently no pain or tenderness, but mother noticed hat arm wats not used as freely as usual. Some swelling of forearm, sliwht tenderness to palpation, definite green-stick fracture (with outward bowing) of ulna. Reduced without ether.

Case XIII. R. K., ago 1 1-2 years. Fell on the lloor 6 days aro. Now seems to have some pain. Green-stick of both bones of right arm, with bowing outward, at upper and middle third.

CAse XIV. L. M., ago 4 years. Fell yesterday and refuses to walk. Will not put left foot down even to stand. No bruise or ecchymosis or swelling. Ontlines normal, but point of tenderness marked a few inches above malleolus on tjoia. Forvible flexjon causes pain, but child will not point out the exact locality. X-ray demonstrates crack or fissure, obligue, and extending through tibia at the mentioned locality.

Case XV. G. 1), age 5 years. Fell yesterday. Child complains of pain on standing or walking. No bruise or swelling. Ontline of tibia normal and tibula springs normally under pressure. These is a tender place on tibia 3 inches above malleolus. X-ray shows an obligue crack through tibia at this locality.

Cask XVI. J. C., agro 11 years. Three weeks ago a carriage wheel fell on his right foot. Has had no treatment. IIas been lame, but has been walking about. Foot swollen, and a slightly tender mass at middlo of shaft of right second metalarsal, apparently callus. Walks with moderate Jimp. J)iagnosis of fracture made. 'The skiagraph showed a complete fracture, with some displacement and much callus. 'This boy was allowed to walk with felt pads and strapping, and did well from the time of beginning treatment.

Cass XVII. H. C., ago is 1-2 years. Run over by a wagon 1 week agro. Ilother complains that child walks lame. Child insists she has no pain, nor will sle admit any tender point, but her evident increase of interest when the foot is pressed over shaft of fourth metatarsal and a slight suspicion of callus at this point suggest fracture. Frature was demonstrated by x-ray.

Case XVIII. W. R., age is years. Fell 5 feet 2 weeks ago, and walks with stiff and slightly everted foot. No bruise; no pain. 'Tenderness only when foot is squeezed together. l'ain is then referred to middle of foot just below baso of metatarsal joint. Nothing felt. X-ray demonstrated a complete racture, with beginuing union, at the base of the third metatarsal.

In addition to these may be noted a fracture of a metacarpal seen at three weeks, an incomplete fracture of the tibia found after one week, and a green-stick of the fibula tirst presented for examination after three weeks, of which no detailed notes are at hand. All were in young children.

These cases are submitted in the notion that we all tend to underestimate the tolerance of children to fractures. In adults there are not infrequent exceptions to the rule that fractures entail immediate and notable pain and disability; in children it would seem that the exceptions are so numerous as to require moditication of the rule. 
In small children, where there is a history of a fall or other trauma, and especially where the ar'm or shoulder girdle may be involved, the only safe way seems to be to assume a fracture as proballe, till every inch of bone has been gone over carefully. Only in this way can we be safe from occasional oversights and from ignominious explanations later on.

\section{NOTES ON X-IAIGIIT.}

HY WHLLAM ROLLING, BOBTON.

VACUUM TUBE BURNS.

'Tue first report I saw of burning from a vacIIIm tube was loy IIawkes, in The Belectrical Revien for $\Lambda$ ug. 12, 1896. IIe stated that the burns were produced by $x$-rays. 'Tesla, in the same journal for Dec. 2, 1896, said they were not due to $x$-rilys but to ozone, and possibly to nitrous acid. In the number for Jan. 5, 189 , I reported that these burns could be produced by electricity when no $x$-light was present. In the Boston Medical and Surgical Journal for Feb. 14, 1901, it was stated that when guinea pigs were protected from all electrical effects they could be killed by $x$-light without any " $x$-ray burns" appearing. In the issue for Feb. 28 it was reported that abortion had heen produced by $x$-light. These results were not accepted. 'That a motion of the ether, of whose existence none of our senses made us conscious, could kill animals was too new and remarkable a fact to be believed. I was told by physicians that guinea pigs were delicate, therefore the experiments proved nothing; that the precautions taken to exclude the participation of electricity in the results were inadequate, that $x$-light could not kill a cryptogam, therefore it was not probable that it could affect one of the higher animals. Lastly, the pathologist to whom some of the material was given appears to have made no use of his opportunities.

Einerson once said that what was excellent was permanent. These were excellent experiments, therefore I report another of them :

Four strong guinea pigs were used. Two were exposed to $x$-light under the conditions mentioned in my notes of Feb. 14 and 28, and March 28, 1901 , for protecting them from the effects of ultraviolet light, electric induction and convection. 'The others were subjected to the same treatment and handling, except that no x-light was allowed to shine upon them. By making the exposures shorter than those mentioned in my earlier notes, it was possible to burn the animals before they were killed.

I have, therefore, certainly proved that " $\mathrm{x}$-ray burns" can be produced by $x$-light when no electricity is present, and by electricity when no $x$-light is present.

The generator used in the experiments was an influence machine with 16 glass plates, averaging 2 metres in diameter. The speed was 120 revolutions a minute. 'The tube had an oxygen vacuum. The diameter of the aluminum cathode was $51 \mathrm{~mm}$.
Its mass was 14 gms. Its radius of curvature was $35.5 \mathrm{~mm}$. The target was of the rotary type. It was made of a disk of platinum-iridium $28 \mathrm{~mm}$. in diameter and $2 \times$ mm. thick. Its distance from the cathorle, unless otherwise stated, was $71 \mathrm{~mm}$. The target was kept red hot with a white hot area where the cathode stream struck. The resistance of the tube with the target at $71 \mathrm{~mm}$. was $14 \mathrm{~mm}$. Fresh oxygen was introduced from a regulator, containing manganese dioxide, when the resistance of the tube rose above $14 \mathrm{~mm}$.

The doulle liaraday chamber employed to contain the pigs was made of tinned iron, .40 of a $\mathrm{mm}$. thick. The side of each chamber toward the vacuum tube was made of aluminum .26 mm. thick. Air was admitted through iron wire gauze with spaces $.70 \mathrm{~mm}$. square between the wires. The gauze was on the side a way from the tube.

When a pig was being exposed his nearest side was $14 \mathrm{~cm}$. from the radiant area of the target. It will be observed that before the $x$-light could shine on a pig it passed through two thicknesses of aluminum, the outer one connected with the earth by a metal wire. It should also be remembered that 'Tesla and others have stated that a single thickness of aluminum was a complete protection against " $x$-ray burns." These experiments showed that not only could burns be produced through such a screen, but that animals could be killed by the light after it had passed through two aluminum screens. What an aluminum screen is able to do is to protect from ultraviolet light, from the ether strain surrounding an excited tube, from electric convection, and from whatever rays it can absorb. The following table gives details of the experiment. The weights are gross. 'To find the net weights deduct the weight of the inner chamber, $357 \mathrm{gms}$. It will be observed that Pig 2 showed practically no external signs of burning though abortion and death resulted. 'This illustrates that animals vary in susceptibility to the external action of $x$-light and warns us to consider these differences when patients are treated by $x$-light. What may be a harmless exposure to one patient may cause a burn in another. Pigs 3 and 4 were placed in the same Faraday chamber as ligs 1 and 2 , remaining there for the same length of time. They were therefore exposed as long to ozone and nitrous fumes and handled as much, yet they remained in perfect liealth. All the pigs lived in the same pen, received the same care and food, the latter in unlimited amount. The whole series of experiments showed we had in $x$-light, after excluding the participation of all other agents in the results, a force of great power, whose action was not understood, whose effects on the tissues were unknown. I failed in my attempt to get a pathologist interested, and as my knowledge of the normal microscopical appearances of the tissues of guinea pigs is insufficient to make my observations worth publishing, I hope some clear-eyed observer will realize that here is a new field where some useful original work can be done. 